\title{
General Aviation Industry Policy Optimization Based on the Perspective of Supply-side Structural Reform
}

\author{
Zou Yuming, Zhang Liang \\ Guangzhou Civil Aviation College, Guangzhou, 510000
}

Keywords: general aviation industry; policy optimization; the perspective of supply-side structure

Abstract: This paper proposes the problems of China's general aviation industry policy at the present stage, based on the perspective of supply-side structure, from the perspective of legislation, decentralization of government, the construction of "functional" industrial policy system, and the evaluation system of industrial policy performance. The idea of optimizing China's general aviation industry policy is to provide reference for the formulation and optimization of general aviation industry policies in the future.

\section{Introduction}

Since August 2010, the State Council and the Central Military Commission issued the "Opinions on Deepening China's Low-Level Airspace Management Reform". Since then, relevant national departments have taken active actions and a series of policies and initiatives to promote the development of general aviation have come one after another; Policies and measures to promote the development of the general aviation industry have also become more and more specific. According to incomplete statistics, from 2010 to the present, the State Council, national ministries and commissions, civil aviation bureaus, and local governments have issued policies to promote the development of the general aviation industry that have reached as many as hundreds. The introduction of these policies has strongly supported the development of the national and local general aviation industry, and has played a significant role in guiding the development of the industry. However, while industrial policy is achieving results, we must also see that there are still many problems in the general aviation industry policy at the current stage, whether it is the setting of policy objectives or the management, implementation, and effects of policies, the structural reforms in the supply side of the development industry under "new age" do not meet the requirements for industrial development efficiency.

2. The Optimization of General Aviation Industry Policy Performance Based on the Perspective of Supply-side Reform

\subsection{Improve the legal system of general aviation industry and realize the legal relevance of policy formulation}

(1) Paying attention to the experience of international general aviation industry legislation and improving the quality of general aviation industry legislation 
The successful experience of the world's most powerful aviation powers shows that a sound and complete legal and regulatory system is the driving force for the sustained, healthy and rapid development of the general aviation industry, and the guarantee for creating a good industrial environment. This requires the general aviation industry legislative work to have an international perspective, fully absorb the legislative experience of the general aviation giant, and continuously improve the quality of the general aviation industry in China. First, it is necessary to fully study and analyze the system and content of general aviation aviation's powerful laws and regulations, seek contents that can be used for reference, and combine with the actual conditions of the development of China's general aviation industry to form a general aviation legal and regulatory system in line with the development of China's general aviation industry. Secondly, the government should comprehensively manage the construction of the general aviation industry's laws and regulations system, accelerate the establishment of adaptations to the development of general aviation, clarify the rights and obligations of the main actors, improve the supporting measures for the development of the industrial chain, and coordinate the development of general aviation equipment manufacturing and operation services. The general aviation laws and regulations system makes it more instructive, normative and feasible for the development of the general aviation industry. The third is to establish an enterprise's participation in the general aviation industry legislative mechanism to enhance the science, democracy, operability, and effectiveness of the general aviation industry legal system.

(2) Formulate a unified general aviation industry legislative plan to enhance the regularity of general aviation industry legislation

Strengthen the leading role of general aviation industry legislation at the government level, formulate programmatic policy documents for industrial legislation, establish a unified general aviation industry legislative plan, determine basic principles that general aviation industry legislation in all fields should abide by, coordinate the development of general aviation industry legislation at the national and local government levels to avoid legislative duplication and conflicts between national and local governments. Plan the relationship between the key areas of general aviation industry legislation, long-term legislation and recent legislation. Improve and perfect working procedures for the formulation of general aviation industry laws and regulations, and enhance the regularity of general aviation industry legislation. It lays a solid foundation for the formulation of a standardized, market-oriented and nationalized general aviation industry law and regulations system.

(3) Strengthen the legislation in the key areas of the general aviation industry and lay the foundation for the establishment of a general aviation law at the national level

The stratification, classification, and subdivision of the fields that are required by the legislative support for the development of the general aviation industry shall be incorporated into the construction of the general aviation laws and regulations system so as to make laws and regulations for general aviation industry activities as relevant as possible. By compiling and revising the existing laws and regulations, the existing and subsequent relations between laws and regulations are straightened out to form a clear and structured legal and regulatory system. At the same time, accelerate the general aviation industry's key areas of legislation, in particular, we should tighten up and improve the legal protection and problems of the reform of low space airspace management, general aviation airport construction planning, basic rights and basic obligations of the main body of general aviation activities, research and development of general aviation manufacturing industry, general aviation tax rate, general aviation safety system construction and other fields.

In addition, due to the regional imbalance in the development of China's general aviation industry, there is a big difference in the level and development scale of general aviation in each regions, each region must formulate a series of laws and regulations that are consistent with the 
characteristics of the development of the general aviation industry in the region, based on the characteristics and scale of its development of the general aviation industry. In this way, it will provide reference and experience for the development of systematic laws and regulations at the national level, and it will also help speed up the development of the general aviation industry in all regions.

(4) The role of active navigation industry associations in the establishment of general aviation industry laws and regulations system

The General Aviation Association refers to a social intermediary organization that is located between the government, enterprises, commodity producers and operators, and provides services, consultation, communication, supervision, fairness, self-discipline, and coordination between them. While establishing a systematic system of general aviation industry laws and regulations, it is necessary to promote various types of navigation associations to play an important role in making up for deficiencies and missing areas in laws and regulations. For example, the navigation association will play a role that cannot be replaced by laws and regulations, such as the homogeneity of the navigation companies and the occurrence of vicious competition in similar areas. Therefore, it is necessary to gradually establish national and local navigation associations to effectively restrict and safeguard the benign operation of public power, fully realize and protect the private rights of economic entities such as general aviation upstream and downstream companies, and build a self-regulating mechanism for the overall economic order of the general aviation industry; promote the rapid and healthy development of China's aviation industry.

\subsection{Strengthen the pace of decentralization in the general aviation industry and stimulate the general aviation industry market vitality at the institutional level}

(1) Improve the design of the deregulatory system for the general aviation industry, and improve the standardization of decentralization

In order to make the general aviation industry's simple and decentralized power continue for a long time, the most important thing is to innovate and institutionalize safeguard design. In the general aviation industry's process of decentralization and decentralization, it is necessary to establish a set of system rules that are sound, well-functioning, and scientifically rigorous, and to regulate the entire process of deregulating the general aviation industry. The deregulation of the general aviation industry is inseparable from the perfect top-level design. The system must be safeguarded to eliminate the internal constraints in the decentralization of power, provide institutional impetus for the decentralization of power, and ensure smooth implementation of the decentralization of the general aviation industry. First, we must establish and improve the system of government power lists. Through the establishment of a system of government power lists, the rigid rules of law are used to clarify the exercise of government responsibilities and powers. Second, establish a general aviation authority for the evaluation of decentralization. Effectively strengthen the government's performance appraisal on the general aviation industry's deregulation and decentralization, keep track of the decentralization process, and timely adjust the reform direction of decentralization in light of the follow-up results, and prompt the reforms to be effective. Third, establish a dual supervision mechanism for the decentralization of power. First, improve the internal supervision system for the general aviation industry in all levels of government, and further strengthen the internal oversight mechanisms at all levels to prevent the failure of supervision after the devolution of power; secondly, we have effectively strengthened the external supervision of the general aviation industry's simple and decentralized powers to ensure that the government's decentralization is truly implemented, and that the decentralization of real power will really benefit the general aviation industry. 
(2) Improve the reform of relevant supporting systems to improve the systemic nature of the general aviation industry

In addition to the top-level design, the general aviation industry has to improve the relevant supporting systems in addition to the top-level design, so that the development of the general aviation industry's policy of decentralization and decentralization is systemic and synergistic, thus providing effective institutional guarantees for smooth and effective implementation. First, deepen the reform of the general aviation administrative approval system. It is necessary to continuously abolish and decentralize the government's examination and approval of general aviation business, highlight the transfer of approval authority in general aviation production and management and industrial management, and increase the market vitality and competitiveness of the general aviation industry. Second, establish and improve the power restriction mechanism. It is necessary to establish a scientific and effective mechanism for restricting and coordinating rights to ensure that the government can exercise the authority of the general aviation industry to decentralize power in accordance with legal rights and procedures. We will further regulate the exercise of government power so as to cut off the source of government's improper interests and eliminate the interest restriction of the general aviation industry's simple and decentralized power.

(3) Focus on multi-party participation to improve the effectiveness of general aviation industry

The deregulation of the general aviation industry is a systematic project. What it needs to do is to understand clearly the various relationships between the government and the general aviation market, the government and general aviation companies, and the government and general aviation social organizations, and it involves all aspects of interests. Therefore, the general aviation industry's simple and decentralized reforms are not only the behavior of the government's main body, but should allow the general aviation companies, general aviation organizations, general aviation research experts and scholars, and even the media public opinion to participate widely. This will help the general aviation industry to take advantage of its own advantages, enhance the scientific and rational reform of the general aviation industry, simplify the decentralization reforms, and ensure the effectiveness of the reform of decentralization.

\subsection{Improve the construction of "functional" industrial policy system and create a good development atmosphere for the development of general aviation enterprises}

(1) Improve financing services for small and medium-sized navigation companies and inject capital into small and medium-sized navigation companies

First, a national policy-based financing service system for small and medium-sized navigation companies was established to provide financing services for the operation and development of small and medium-sized general aviation companies. Form a sound system of credit guarantee for small and medium-sized navigation companies. The credit guarantee fund is mainly funded by the government. Other agencies, groups and related commercial banks jointly fund the establishment of specialized agencies to provide guarantee funds for the small and medium-sized shipping companies to the loan banks. The relevant government departments shall establish financing support policies and financing guarantee funds, guarantee the specific financing businesses through various selected guarantee companies, and finally complete the final financing through commercial banks. Second, moderately liberalize private financing control, formulate relevant laws and regulations, and formulate a "private lending law" that helps solve the financing of small and medium-sized navigation companies, and regulate the scope of responsibility of each relevant economic entity in legal form. Third, liberalize private capital to establish a threshold for financial institutions targeting small and medium-sized navigation companies, encourage the development of small and medium-sized financial institutions whose main business serves small and medium-sized 
shipping companies, and reduce the credit costs of small and medium-sized navigation companies through geographical advantages and professional advantages, and expand credit services. The scope of coverage enables the effective financing of diverse financing needs of different stages of development of small and medium-sized navigation companies.

(2) Improve fiscal and taxation policies for small and medium-sized navigation companies to improve the financial and tax support for small and medium-sized navigation companies

To improve the fiscal and taxation policies for small and medium-sized navigation companies, we must first define the scope of small and medium-sized navigation companies that incorporate the tax support policy system. In this process, it is necessary to avoid the improper entry of large-scale navigation companies, and it is even more necessary to prevent some small and medium-sized navigation companies from being excluded from preferential treatment. Second, from the development difficulties of small and medium-sized navigation companies to implement targeted tax support policies, further reduce the current level of preferential tax rates used by small and medium-sized navigation companies, leaving more profits to enterprises and enhancing their development stamina; We will adjust the current VAT and business tax thresholds for small and medium-sized navigation companies, greatly increase the level of exemption, and abolish the policy of using sales as the standard for VAT general taxpayers. Third, improve tax collection and management services for small and medium-sized navigation companies. Simplify the tax declaration procedures for small and medium-sized navigation companies, further promote and improve the e-filing tax system, change the tax service mode for small and medium-sized navigation companies, and strive to fully implement the tax incentives for all qualified small and medium-sized navigation companies.

(3) Give play to the role of the association as a bridge to create a platform for the development of small and medium-sized navigation companies

It is an important function of the industry association at this stage to give play to the management functions of the navigation associations, to supplement government management gaps, and to create platforms for the development of small and medium-sized navigation companies. Specifically, it should start from the following aspects: First, collect and disseminate information on the navigable market to improve the market resilience of small and medium-sized navigation companies. The Association uses its own information advantages to regularly publish various information to member companies, allowing companies to accurately grasp the latest trends in the navigation market, and provide reference for the production and business activities of enterprises; Secondly, to carry out the training of general aviation professional and technical personnel, comprehensively improve the overall quality of small and medium-sized navigation company personnel, carry out technical training for the small and medium-sized navigation companies who are in urgent need of professional talents, and solve small and medium-sized schools by asking them to come to school, go on to teach, and conduct class training. The current situation of the shortage of talents in navigation companies; once again, maintain the interests of small and medium-sized navigation companies. The industry association is the home of the enterprise and the legitimate representative of the enterprise. Therefore, safeguarding the rights and interests of the enterprises in the industry is also an important service content of the industry associations. It includes providing legal assistance for member companies, unfair competition, unfulfilling compliance, and damaging the image of the industry.

\subsection{Establish general aviation industry policy performance evaluation system to ensure the supply capability of general aviation industry policy}

(1) Strengthen the top-level design and establish a working mechanism for evaluating the entire process of general aviation industry policy 
From the perspective of enhancing the general aviation industry's supply capacity and enhancing the industrial development soft power, we must fully understand the importance of policy assessment to the development of the general aviation industry. The customer service only pays attention to the policy formulation, ignores the drawbacks of the policy evaluation, and incorporates the policy evaluation into the policy formulation process. The General Aviation Industry Policy Evaluation Leading Group was set up to raise the awareness of the main responsibility of the policy evaluation, coordinate the leadership and plan the construction of the policy evaluation mechanism, formulate a detailed policy evaluation strategic plan and indicator system, and conduct dynamic tracking and adjustment. First, policy evaluation must be conducted throughout the formulation, implementation, adjustment, and termination of the entire policy cycle. Once the policy is made, it must be inspected and evaluated. It should be evaluated once every once in a while, and problems should be solved in a timely manner. Second, efforts should be made to increase the level of policy formulation. Adequate prior assessment should be made. In particular, assessment of groundbreaking policies should allow trial and error, and conclusions should be cautious. Third, the assessment results should be promptly fed back to the superior and related departments. The fourth is to use "public participation, expert argumentation, risk assessment, legitimacy review, and collective discussion decision as the necessary procedures for major decision-making." A debate mechanism should be introduced to debate major policy assessments. The fifth is to use the assessment as a means of power control and institutionalization, combined with the lifelong accountability system for major decisions, in order to regulate the operation of power. Sixthly, it is necessary to rationally determine the assessment and consultation procedures, improve the democratization, legalization, and scientific policy decision-making process, and ensure the independence and scientificness of the evaluation work from the institutional perspective.

(2) Integrate existing policy assessment resources and build a diversity policy assessment mechanism

Integrate existing policy assessment resources both inside and outside the industry, and build a diversified policy assessment mechanism that the government is responsible for, and that social organizations are widely involved, and that the mass media actively cooperate. To formulate a midand long-term development plan for optimizing general aviation industry policy assessment and consultation mechanism, carry out special research on assessment and consultation system, and define overall objectives, key tasks, work standards, incentive evaluation mechanisms, and funding and legal safeguard measures; taking openness, practicality, and efficiency as the construction ideas, focusing on innovative mechanisms, and gradually absorbing, reforming, integrating, and innovating, we have gradually established the features suitable for the development of the general aviation industry, which have obvious comprehensive advantages, outstanding decision-making service capabilities, scientific efficiency, and full of vitality. Dynamic diversification policy research and evaluation consulting mechanism; Explore new approaches and new methods for policy evaluation feedback, strengthen the intelligent construction of policy evaluation, and build a comprehensive database or data sharing platform for general aviation industry policy evaluation; establish a diversified platform for policy evaluation exchanges and results dissemination, facilitate an effective competitive market for policy assessment, coordinate various relationships in assessment and consultation, facilitate the acquisition of relevant policy assessment information from multiple sources, promote policy improvement, and ensure normal policy evaluation. It regards it as an important learning tool and method to promote the improvement of policy level; establish a standardized policy evaluation management system, establish rules and regulations ensure that the assessment conforms to the Party's line, principles, and policies, and complies with national laws and regulations. 


\section{Conclusion}

Based on the above analysis, in the future, China's general aviation industry development should focus on general aviation industry development planning policies, general aviation industry financial investment policies, general aviation industry financial support measures, general aviation industry enterprises industry access control measures, and general aviation industry research support policies. In five aspects, adjustments were made to optimize the strategy and strive to achieve a major breakthrough in the development of the general aviation industry, achieve significant results in the adjustment of the internal structure of the industry, and finally form a group of general aviation enterprises with industry leading and demonstration roles, so as to achieve the core competitiveness of China's general aviation industry.

\section{References}

[1] http://www.doc88.com/p-4972197814779.html.

[2] Chen Yonggang. Research on the Construction of General Aviation Safety Management System in China [J]. China Safety Science and Technology, 2012, 08(6):216-220.

[3] Wang Jingyi. Research on Zhuzhou General Aviation Industry Development Strategy Based on Industrial Cluster Theory [D]. Hunan University of Technology, 2016. 